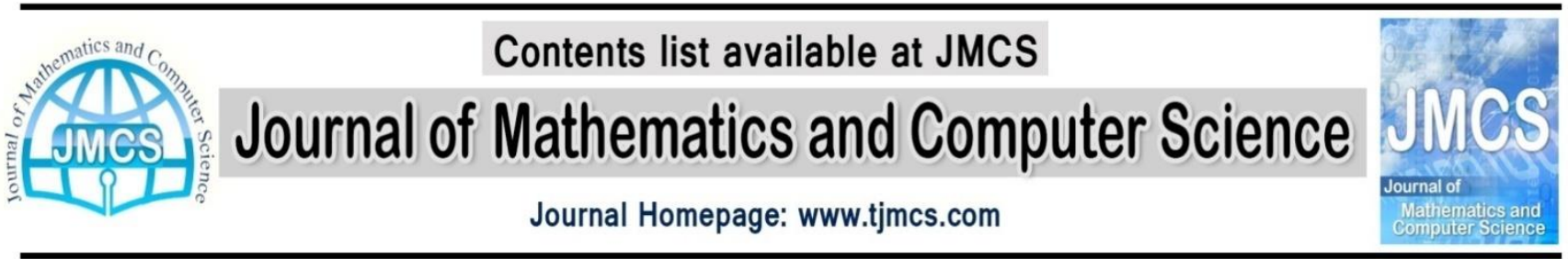

\section{Wasting the Percentage of On-hand Inventory in an Instantaneous Economic Order Quantity Model Due to Deterioration}

\author{
M. Pattnaik \\ Dept. of Business Administration, \\ Utkal University, Bhubaneswar, India \\ monalisha_1977@yahoo.com
}

\begin{abstract}
Article history:
Received March 2013

Accepted Apri 2013

Available online May 2013
\end{abstract}

Available online May 2013

\section{Abstract}

In this paper the traditional instantaneous economic order quantity model is extended to allow the percentage of on-hand inventory is wasted due to deterioration. That is, the wasted/ no wasted percentage of on-hand inventories in instantaneous EOQ models due to deterioration are considered simultaneously. For any given number of replenishment cycles the existence of a unique optimal replenishment schedule is proved and further the concavity of the total profit function of the inventory system in the number of replenishments is established. A new mathematical model is developed and considered as an enhancement to the EOQ model so that the net profit is maximized and the numerical analysis show that an appropriate policy can benefit the retailer and that policy is important, especially for wasting of deteriorating items. Finally, sensitivity analysis of the optimal solution with respect to the major parameter, percentage of onhand inventory which is lost due to deterioration is also carried out.

Keywords: EOQ, Deterioration, Units lost, Crisp, Profit

\section{Introduction}

Inventory management plays a crucial role in businesses since it can help companies reach the goal of ensuring prompt delivery, avoiding shortages, helping sales at competitive prices and so forth. The mathematical modeling of real-world inventory problems necessitates the simplification of assumptions to make the mathematics flexible. However, excessive simplification of assumptions results in mathematical models that do not represent the inventory situation to be analyzed.

Many models have been proposed to deal with a variety of inventory problems. The classical analysis of inventory control considers three costs for holding inventories. These costs are the procurement cost, carrying cost and shortage cost. The classical analysis builds a model of an inventory system and calculates the EOQ which minimize these three costs so that their sum is satisfying minimization criterion. One of the unrealistic assumptions is that items stocked preserve their physical characteristics during their stay in inventory. Items in stock are subject to many possible risks, e.g. damage, spoilage, dryness; vaporization etc., those results decrease of usefulness of the original one and a cost is incurred to account for such risks. 
The EOQ inventory control model was introduced in the earliest decades of this century and is still widely accepted by many industries today. Comprehensive reviews of inventory models can be found in [9], [14] and [17]. In previous deterministic inventory models, many are developed under the assumption that demand is either constant or stock dependent for deteriorated items. [7] developed a stochastic dynamic programming model presented for determining the optimal ordering policy for a perishable or potentially obsolete product so as to satisfy known time-varying demand over a specified planning horizon. They assumed a random lifetime perishability, where, at the end of each discrete period, the total remaining inventory either becomes worthless or remains usable for at least the next period. [8] explored the inventory model for time dependent holding cost and deterioration with salvage value where shortages are allowed. [3] examined the simultaneous selection product durability and order quantity for items that deteriorate over time. Their choice of product durability is modeled as the values of a single design parameter that effects the distribution of the time-to-onset of deterioration (TOD) and analyzed two scenarios; the first considers TOD as a constant and the store manager may choose an appropriate value, while the second assumes that TOD is a random variable. [2] considers the effect of different marketing policies, e.g. the price per unit product and the advertisement frequency on the demand of a perishable item. [1] considered an economic order quantity (EOQ) inventory model for deteriorating goods developed with a linear, positive trend in demand allowing inventory shortages and backlogging. [1] and [5] considered the effects of inflation and the time-value of money with the assumption of two inflation rates rather than one, i.e. the internal (company) inflation rate and the external (general economy) inflation rate. [4] argued that the analysis of [1] contained mathematical errors for which he proposed the correct theory for the problem supplied with numerical examples. [11] explained a single item EOQ model with demand dependent unit cost and variable setup cost. [10] presented an EOQ inventory model for perishable items with a stock dependent selling rate. They assumed that the selling rate is a function of the current inventory level and the rate of deterioration is taken to be constant. Unlike the work of [18] who studied the case of partial backlogging. [10] considered the cases of no backlogging, and of partial and full backlogging.

The most recent work found in the literature is that of [6] who extended his earlier work by assuming a time-varying demand over a finite planning horizon. [11] who assumes instant deterioration of perishable items with constant demand where discounts are allowed. [12] presented an entropic order quantity (EnOQ) model under instant deterioration for perishable items with constant demand where discounts are allowed. [15] studied an EOQ inventory model in which it assumes that the percentage of on-hand inventory wasted due to deterioration is a key feature of the inventory conditions which govern the item stocked.

[16] studied profit maximization economic order quantity model for deteriorated items with time and price dependent linear and decreasing demand for finite planning horizon under promotion factor for acquiring more profit. In this paper, replenishment decision under wasting the percentage of on-hand inventory due to deterioration are adjusted arbitrarily upward or downward for profit maximization model in response to the change in market demand within the finite planning horizon. The objective of this paper is to determine optimal replenishment quantities in an instantaneous replenishment profit maximization model.

All mentioned above inventory literatures with deterioration or no wasting the percentage of onhand inventory due to deterioration have the basic assumption that the retailer owns a storage room with optimal order quantity. In recent years, companies have started to recognize that a tradeoff exists between product varieties in terms of quality of the product for running in the market smoothly. In the absence of a proper quantitative model to measure the effect of product quality of the product, these companies have mainly relied on qualitative judgment. This paper postulates that measuring the behavior of production systems may be achievable by incorporating the idea of retailer in making optimum decision on replenishment with wasting the percentage of on-hand inventory due to deterioration and then compares the optimal results with no wasting the percentage of on-hand inventory due to deterioration traditional model. The major assumptions used in the above research articles are summarized in Table1. 
Table - 1 Summary of the Related Researches

\begin{tabular}{|c|c|c|c|c|c|c|c|}
\hline $\begin{array}{c}\text { Author(s) } \\
\text { and } \\
\text { published } \\
\text { Year }\end{array}$ & $\begin{array}{c}\text { Structure } \\
\text { of the } \\
\text { model }\end{array}$ & Demand & $\begin{array}{c}\text { Demand } \\
\text { patterns }\end{array}$ & Deterioration & Planning & $\begin{array}{c}\text { Units Lost due } \\
\text { Deterioration }\end{array}$ & Model \\
\hline $\begin{array}{c}\text { Hariga } \\
(1994)\end{array}$ & $\begin{array}{c}\text { Crisp } \\
\text { (EOQ) }\end{array}$ & Time & $\begin{array}{c}\text { Non- } \\
\text { stationary }\end{array}$ & Yes & Finite & No & Cost \\
\hline $\begin{array}{c}\text { Tsao et al. } \\
(2008)\end{array}$ & $\begin{array}{c}\text { Crisp } \\
\text { (EOQ) }\end{array}$ & Time and Price & $\begin{array}{c}\text { Linear and } \\
\text { Decreasing }\end{array}$ & Yes & Finite & No & Profit \\
\hline $\begin{array}{c}\text { Pattnaik } \\
(2009)\end{array}$ & $\begin{array}{c}\text { Crisp } \\
\text { (EnOQ) }\end{array}$ & $\begin{array}{c}\text { Constant } \\
\text { (Deterministic) }\end{array}$ & Constant & $\begin{array}{c}\text { Yes } \\
\text { (Instant) }\end{array}$ & Finite & No & Profit \\
\hline $\begin{array}{c}\text { Pattnaik } \\
(2011)\end{array}$ & $\begin{array}{c}\text { Crisp } \\
\text { (EOQ) }\end{array}$ & $\begin{array}{c}\text { Constant } \\
\text { (Deterministic) }\end{array}$ & Constant & $\begin{array}{c}\text { Yes } \\
\text { (Instant) }\end{array}$ & Finite & No & Profit \\
\hline $\begin{array}{c}\text { Present } \\
\text { Paper } \\
(2012)\end{array}$ & $\begin{array}{c}\text { Crisp } \\
\text { (EOQ) }\end{array}$ & $\begin{array}{c}\text { Constant } \\
\text { (Deterministic) }\end{array}$ & Constant & $\begin{array}{c}\text { Yes } \\
\text { (Wasting) }\end{array}$ & Finite & Yes & Profit \\
\hline
\end{tabular}

The remainder of the paper is organized as follows. In section 2 assumptions and notations are provided for the development of the model. The mathematical formulation is developed in section 3 . The solution procedure is given in section 4. In section 5, numerical example is presented to illustrate the development of the model. The sensitivity analysis is carried out in section 6 to observe the changes in the optimal solution. Finally section 7 deals with the summary and the concluding remarks.

\section{Notations and Assumptions}

$\mathrm{r} \quad$ Consumption rate

$t_{c} \quad$ Cycle length

h Holding cost of one unit for one unit of time.

$\mathrm{HC}$ (q) Holding cost per cycle

K Setup cost per cycle

c Purchasing cost per unit

$\mathrm{P}_{\mathrm{s}} \quad$ Selling Price per unit

$\alpha \quad$ Percentage of on-hand inventory that is lost due to deterioration

q Order quantity

$\mathrm{q}^{* *} \quad$ Modified economic ordering / production quantity (EOQ/EPQ)

q* Traditional economic ordering quantity (EOQ)

$\varphi(t) \quad$ On-hand inventory level at time $t$

$\pi_{1}(q) \quad$ Net profit per unit of producing q units per cycle in crisp strategy

$\pi$ (q) Average profit per unit of producing q units per cycle in crisp strategy

\section{Mathematical Model}

Denote $\varphi(t)$ as the on-hand inventory level at time t. During a change in time from point $t$ to $t+d t$, where $t+d t>t$, the on-hand inventory drops from $\varphi(t)$ to $\varphi(t+d t)$. Then $\varphi(t+d t)$ is given as:

$\varphi(\mathrm{t}+\mathrm{dt})=\varphi(\mathrm{t})-\mathrm{rdt}-\alpha \varphi(\mathrm{t}) \mathrm{dt}$

Equation (1) can be re-written as: $\frac{\varphi(\mathrm{t}+\mathrm{dt})-\varphi(\mathrm{t})}{d t}=-r-\alpha \varphi(\mathrm{t})$

and $\mathrm{dt} \rightarrow 0$, equation (2) reduces to: $\frac{\mathrm{d} \varphi(\mathrm{t})}{d t}+\alpha \varphi(\mathrm{t})+\mathrm{r}=0$

Equation (3) is a differential equation, solution is

$\varphi(t)=\frac{-r}{\alpha}+\left(q+\frac{r}{\alpha}\right) \times e^{-\alpha t}$

Where $\mathrm{q}$ is the order quantity which is instantaneously replenished at the beginning of each cycle of length $t_{c}$ units of time. The stock is replenished by q units each time these units are totally depleted as a result of outside demand and deterioration. The cycle length, $t_{c}$, is 
determined by first substituting $t_{c}$ into equation (4) and then setting it equal to zero to get: $t_{c}=$ $\frac{1}{\alpha} \ln \left(\frac{\propto \mathrm{q}+\mathrm{r}}{\mathrm{r}}\right)$

Equation (4) and (5) are used to develop the mathematical model. It is worthy to mention that as $\alpha$ approaches to zero, $t_{c}$ approaches to $\frac{\mathrm{q}}{\mathrm{r} \rho}$. Then the total number of units lost per cycle, $\mathrm{L}$, is given as:

$L=r\left[\frac{q}{r}-\frac{1}{\alpha} \ln \left(\frac{\alpha q+r}{r}\right)\right]$

The total cost per cycle, TC(q), is the sum of the procurement cost per cycle, $\mathrm{K}+\mathrm{cq}$, and the holding cost per cycle, $\mathrm{HC}(\mathrm{q})$. $\mathrm{HC}(\mathrm{q})$ is obtained from equation (4) as :

$$
\begin{aligned}
H C(q) & =\int_{0}^{t c} h \varphi(t) d t=h \int_{0}^{\frac{1}{\alpha} \ln \left(\frac{\alpha \mathrm{q}+\mathrm{r}}{\mathrm{r}}\right)}\left[-\frac{\mathrm{r}}{\alpha}+\left(\mathrm{q}+\frac{\mathrm{r}}{\alpha}\right) \times \mathrm{e}^{-\alpha \mathrm{t}}\right] d t \\
& =h \times\left[\frac{q}{\alpha}-\frac{r}{\alpha^{2}} \ln \left(\frac{\alpha q+r}{r}\right)\right]
\end{aligned}
$$

$\mathrm{TC}(\mathrm{q})=\mathrm{K}+\mathrm{cq}+h \times\left[\frac{q}{\alpha}-\frac{r}{\alpha^{2}} \ln \left(\frac{\alpha q+r}{r}\right)\right]$

The total cost per unit of time, TCU (q), is given by dividing equation (8) by equation (5) to give:

$\operatorname{TCU}(\mathrm{q})=\left[K+\mathrm{cq}+h \times\left[\frac{q}{\alpha}-\frac{r}{\alpha^{2}} \ln \left(\frac{\alpha q+r}{r}\right)\right]\right] \times\left[\frac{1}{\alpha} \ln \left(\frac{\alpha \mathrm{q}+\mathrm{r}}{\mathrm{r}}\right)\right]^{-1}$

$=\frac{K \propto+(c \propto+h) q}{\ln \left(1+\frac{\alpha q}{r}\right)}-\frac{h r}{\alpha}$

As $\alpha$ approaches zero, then equation (9) reduces to TCU (q) $=\frac{K r}{q}+c r+\frac{h q}{2}$

Whose solution is given by the traditional EOQ formula, $q^{*}=\sqrt{\frac{2 K r}{h}}$. The total profit per cycle is $\pi_{1}(\mathrm{q})$.

$$
\begin{aligned}
\pi_{1}(\mathrm{q})= & (\mathrm{q}-\mathrm{L}) \times P_{S}-\mathrm{TC}(\mathrm{q}) \\
= & (\mathrm{q}-\mathrm{L}) \times P_{S}-\mathrm{K}-\mathrm{cq}-\mathrm{h} \times\left[\frac{q}{\alpha}-\frac{r}{\alpha^{2}} \times \ln \left(\frac{\alpha q+r}{r}\right)\right]
\end{aligned}
$$

Where $\mathrm{L}$, the number of units lost per cycle due to deterioration, and TC (q) the total cost per cycle, are calculated from equations (6) and (8), respectively. The average profit $\pi(q)$ per unit time is obtained by dividing $\mathrm{t}_{\mathrm{c}}$ in $\pi_{1}(\mathrm{q})$. Hence the profit maximization problem is

Maximize $\pi_{1}(\mathrm{q})$

$\forall \mathrm{q}>0$

\section{Solution Procedure (Optimization)}

The optimal ordering quantity q per cycle can be determined by differentiating equation (10) with respect to q, then setting these to zero.

In order to show the uniqueness of the solution in, it is sufficient to show that the net profit function throughout the cycle is concave in terms of ordering quantity q. The second order derivates of equation (10) with respect to q are strictly negative. Consider the following propositions.

Proposition 1.The net profit $\pi_{1}$ (q) per cycle is concave in $q$.

Conditions for optimal $\mathrm{q}$

$\frac{\mathrm{d} \pi_{1}(q)}{d q}=\frac{r}{\alpha q+r}\left(P_{s}+\frac{h}{\alpha}\right)-\left(c+\frac{h}{\alpha}\right)=0$

The second order derivative of the net profit per cycle with respect to q can be expressed as 


$$
\frac{d^{2} \pi_{1}(q)}{d q^{2}}=-\frac{r}{(\alpha q+r)^{2}}\left(P_{s} \alpha+h\right)
$$

Since $r>0$ and $\mathrm{P}_{\mathrm{s}} \boldsymbol{\alpha}+\boldsymbol{h}>\mathbf{0}$ equation (13) is negative.

Propositions 1 shows that the second order derivative of equation (11) with respect to q are strictly negative.

The objective is to determine the optimal values of $\mathrm{q}$ to maximize the unit profit function of equation (11). It is very difficult to derive the optimal values of $q$, hence unit profit function. There are several methods to cope with constraints optimization problem numerically. But here LINGO 13.0 software is used to derive the optimal values of the decision variables.

\section{Numerical Example}

Consider an inventory situation where K is Rs. 200 per order, h is Rs. 5 per unit per unit of time, $\mathrm{r}$ is 1200 units per unit of time, c is Rs. 100 per unit, the selling price per unit $\mathrm{P}_{\mathrm{s}}$ is Rs. 125 and $\alpha$ is $5 \%$, . The optimal solution that maximizes equation (10) and $\mathrm{q}^{* 8}$ andq $\mathrm{q}^{*}$ are determined by using LINGO 13.0 version software and the results are tabulated in Table 2.

Table-2 Optimal Values of the Proposed Model

\begin{tabular}{|c|c|c|c|c|c|c|}
\hline Model & Iteration & $\mathrm{t}^{*}$ & $\mathrm{~L}^{*}$ & $\mathbf{q}$ & $\pi_{1}(\mathrm{q})$ & $\pi(\mathrm{q})$ \\
\hline Crisp & 72 & 0.1820209 & 0.9969710 & $\mathrm{q}^{* *}=219.4221$ & 5061.233101 & 27805.78 \\
\hline Crisp & 41 & 0.2581989 & - & $\mathrm{q}^{*}=309.8387$ & 7345.967846 & 28450.81 \\
\hline $\begin{array}{c}\% \\
\text { Change }\end{array}$ & - & 41.85124 & - & 41.206697 & 45.1418597 & 2.31977 \\
\hline
\end{tabular}

\section{Sensitivity Analysis}

It is interesting to investigate the influence of $\alpha$ on retailer behaviour. The computational results shown in Table 3 indicates the following managerial phenomena: when the percentage of on-hand inventory that is lost due to deterioration $\alpha$ increases, the replenishment cycle length, the optimal replenishment quantity, optimal net profit per unit per cycle and optimal average profit per unit per cycle decrease respectively. The optimal total number of units lost per cycle increases with increases in the percentage value of the major parameter $\alpha$.

Table-3 Sensitivity Analysis of $\alpha$

\begin{tabular}{|c|c|c|c|c|r|r|c|}
\hline$\alpha \%$ & Iteration & $\mathrm{t}^{*}$ & $\mathrm{~L}^{*}$ & $\mathrm{q}^{* *}$ & $\pi_{1}(\mathrm{q})$ & $\pi(\mathrm{q})$ & $\%$ Change in $\pi(\mathrm{q})$ \\
\hline .01 & 137 & 0.2355173 & 0.3330718 & 282.9538 & 6665.676569 & 28302.28 & 1.785599972 \\
\hline .02 & 83 & 0.2179011 & 0.5705991 & 262.0519 & 6137.323938 & 28165.64 & 1.294191352 \\
\hline .04 & 84 & 0.1919580 & 0.8866168 & 231.2362 & 5359.250447 & 27918.87 & 0.406713910 \\
\hline .10 & 91 & 0.1483355 & 1.326757 & 179.3293 & 4051.051405 & 27310.06 & -1.7827948 \\
\hline .15 & 73 & 0.1282734 & 1.490410 & 155.4185 & 3449.480812 & 26891.63 & -3.28762581 \\
\hline .30 & 91 & 0.0966502 & 1.697797 & 117.6781 & 2501.430181 & 25881.27 & -6.92125882 \\
\hline
\end{tabular}

\section{Conclusions}

In this paper, a modified EOQ model is introduced which investigates the optimal order quantity assumes that a percentage of the on-hand inventory is wasted due to deterioration as a characteristic feature and the inventory conditions govern the item stocked. This paper provides a useful property for finding the optimal profit and ordering quantity with deteriorated units of lost sales. A new mathematical model is developed and compared to the traditional EOQ model numerically. The economic order quantity, $\mathrm{q}^{* 8}$ and the net profit for the modified model, were found to be less than that of the traditional, $\mathrm{q}^{*}$. i.e. $\mathrm{q}^{* 8}<\mathrm{q}^{*}$ and the net profit respectively. But the modified average profit per unit per cycle is more than that of the traditional profit per unit per cycle. Finally, wasting the percentage of on-hand inventory 
due to deterioration effect was demonstrated numerically to have an adverse effect on the average profit per unit per cycle. Hence the utilization of units lost due to deterioration makes the scope of the application broader. Further, a numerical example is presented to illustrate the theoretical results, and some observations are obtained from sensitivity analysis with respect to the major parameter $\alpha$. The model in this study is a general framework that considers wasting/ no wasting the percentage of on-hand inventory due to deterioration simultaneously.

In the future study, it is hoped to further incorporate the proposed model into several situations such as shortages are allowed and the consideration of multi-item problem. Furthermore, it may also take partial backlogging into account when determining the optimal replenishment policy.

\section{References}

[1] S. Bose, A. Goswami, K.S. Chaudhuri, "An EOQ model for deteriorating items with linear timedependent demand rate and shortages under inflation and time discounting". Journal of Operational Research Society, (1995) 46: 775-782.

[2] S.K Goyal, A. Gunasekaran, "An integrated production-inventory-marketing model for deteriorating items". Computers and Industrial Engineering, (1995) 28: 755-762.

[3] D. Gupta, Y. Gerchak, "Joint product durability and lot sizing models". European Journal of Operational Research, (1995) 84: 371-384.

[4] M. Hariga, "An EOQ model for deteriorating items with shortages and time-varying demand". Journal of Operational Research Society, (1995) 46:398-404.

[5] M. Hariga, "An EOQ model for deteriorating items with time-varying demand". Journal of Operational Research Society, (1996) 47:1228-1246.

[6] M. Hariga, "Economic analysis of dynamic inventory models with non-stationary costs and demand". International Journal of Production Economics, (1994) 36: 255-266.

[7] K. Jain, E. Silver, "A lot sizing for a product subject to obsolescence or perishability". European Journal of Operational Research, (1994) 75: 287-295.

[8] V.K. Mishra, "Inventory model for time dependent holding cost and deterioration with salvage value and shortages". The Journal of Mathematics and Computer Science, (2012) 4(1): 37-47.

[9] J.S. Osteryoung, D.E. Mc Carty, W.L Reinhart., "Use of EOQ models for inventory analysis". Production and Inventory Management, $3^{\text {rd }} Q$ tr. , (1986) 39-45.

[10] G. Padmanabhan, P. Vrat, "EOQ models for perishable items under stock dependent selling rate". European Journal of Operational Research, (1995) 86: 281-292.

[11] M. Pattnaik, "A note on nonlinear optimal inventory policy involving instant deterioration of perishable items with price discounts". The Journal of Mathematics and Computer Science, (2011) 3(2): 145-155.

[12] M. Pattnaik, "An entropic order quantity (EnOQ) model under instant deterioration of derishable items with price discounts". International Mathematical Forum, (2010) 5(52): 2581-2590.

[13] M. Pattnaik, "Decision-making for a single item EOQ model with demand-dependent unit cost and dynamic setup cost". The Journal of Mathematics and Computer Science, (2011) 3(4), 390395.

[14] F. Raafat, "Survey of literature on continuously deteriorating inventory models". Journal of Operational Research Society, (1991) 42: 89-94.

[15] M.K. Salameh, M.Y. Jaber, N. Noueihed, "Effect of deteriorating items on the instantaneous replenishment model". Production Planning and Control, (1993) 10(2): 175-180.

[16] Y.C. Tsao, G.J. Sheen, "Dynamic pricing, promotion and replenishment policies for a deteriorating item under permissible delay in payment". Computers and Operations Research, (2008) 35: 3562-3580.

[17] C.D.J. Waters, "Inventory Control and Management”. (Chichester: Wiley), 1994.

[18] H.M. Wee, "Economic Production lot size model for deteriorating items with partial backordering". Computers and Industrial Engineering, (1993) 24: 449-458. 